\title{
Penentuan Jarak Minimum dalam Suatu Jaringan Listrik dengan Algoritma Prim dan QM for Windows (Studi Kasus Pada Perumahan Nelayan di Kota Palopo)
}

\author{
Riswan \\ Institut Agama Islam Negeri (IAIN) Palopo \\ Jl. Agatis, Kel. Balandai, Kota Palopo, Sulawesi Selatan, Indonesia \\ E-mail: riswaniainpalopo@gmail.com
}

Article History:

Received: $\mathrm{xx}-\mathrm{xx}-\mathrm{xxxx}$; Received in revised form: $\mathrm{xx}-\mathrm{xx}-\mathrm{xxxx}$; Accepted: $\mathrm{xx}-\mathrm{xx}-\mathrm{xxxx}$;

Available online: $\mathrm{xx}-\mathrm{xx}-\mathrm{xxxx}$

\begin{abstract}
This study aims to be considered in the planning of cabling on fishermen housing in the city of Palopo. And used as a comparison in determining the minimum distance in the electricity network. The research method used is a quantitative analysis approach. The results of the study are 1. Prim \& QM Algorithm for Windows can be used to solve the problem of electricity distribution cases in Fisherman Housing in Palopo; 2. Prim Algorithm can produce a minimum distance $(300 \mathrm{~m})$ in the electricity distribution network in the Palopo City Fisherman Housing; 3. QM for Windows can produce a minimum distance (300m) in the electricity distribution network in Palopo Fisherman Housing.
\end{abstract}

Keywords: Prim Algorithm; Minimum Distance; Graph; QM for Windows.

Abstrak

Penelitian ini bertujuan untuk dijadikan pertimbangkan dalam perencanaan pemasangan kabel pada perumahan nelayan di kota palopo. Serta dijadikan perbandingan dalam penentuan jarak minimun dalam jaringan listrik. Metode penelitian yang digunakan adalah pendekatan analisis kuantitatif. Hasil penelitian yaitu 1. Algoritma Prim \& QM for Windows dapat digunakan untuk menyelesaikan masalah kasus pendistribusian listrik di Perumahan Nelayan dikota Palopo; 2. Algoritma Prim dapat menghasilkan jarak minimum (300 m) pada jaringan pendistribusian listrik di Perumhan Nelayan kota Palopo; 3. QM for Windows dapat menghasilkan jarak minimum $(300 \mathrm{~m})$ pada jaringan pendistribusian listrik di Perumhan Nelayan Palopo.

Kata Kunci: Algoritma Prim; Jarak Minimum; Graph; QM for Windows.

CProdi Tadris Matematika FTIK IAIN Palopo. This is an open access article under the Creative Commons - Attribution-ShareAlike 4.0 International license (CC BY-SA 4.0) 


\section{Pendahuluan}

Penelitian Operasional dimulai sejak revolusi industri merupakan bagian dari pengaplikasian matematika dalam memecahkan masalahmasalah optimasi. Penelitian Operasional sering dikaitkan secara eksklusif dengan penggunaan teknik-teknik matematika untuk memodelkan dan menganalisis masalah-masalah pengambilan keputusan. Disamping teknikteknik itu, masalah pengambilan keputusan juga mencakup faktor-faktor penting lainnya yang tidak dapat diterjemahkan secara langsung ke dalam model-model matematika. Faktor-faktor itu adalah adanya unsur manusia di dalam setiap pengambilan keputusan ${ }^{1}$

Keberhasilan suatu teknik pada Penelitian Operasional diukur dari penggunaan teknik tersebut sebagai suatu alat pengambil keputusan untuk solusi yang optimal. Sejak diperkenalkan pada tahun 1996 rancang oleh Howard J. Weiss, QM For windows telah terbukti sebagai salah satu alat Penelitian Operasional yang paling baik dan lebih efisien. QM For windows merupakan model dari Penelitian Operasional yang dapat digunakan untuk menganalisis suatu jaringan seperti jaringan transportasi, listrik, air ataupun jaringan telekomunikasi yang sering kita jumpai sehari-hari ${ }^{2}$.

Penelitian ini akan membahas mengenai aplikasi matematika, dalam hal ini adalah Algoritma Prim dan QM For windows untuk pohon rentang minimum pada masalah pendistribusian listrik di Rumah Nelayan Kota Palopo.

Graf didefinisikan sebagai: $G=(\mathrm{V}, \mathrm{E})$, dimana $\mathrm{V}$ merupakan himpunan tidak kosong dari setiap simpul pada himpunan $\{\mathrm{v} 1, \mathrm{v} 2, \ldots, \mathrm{vn}\}$ dan E adalah himpunan sisi yang menghubungkan sepasang simpul di himpunan \{ e1, e2,..., en\}. Beberapa terminologi dasar dalam graf yang perlu diketahui adalah sebagai berikut:

1. Graf berbobot adalah graf yang setiap sisinya diberi sebuah bobot.

${ }^{1}$ Hamdy A Taha, Operations Research An Introduction, 9th ed. (London: Pearson International, 2011).

2 Arogundade 0. T., Sobowale B., and Akinwale A. T., "Prim Algorithm Approach to Improving Local Access Network in Rural Areas," International Journal of Computer Theory and Engineering, 2011, 413-17, https://doi.org/10.7763/IJCTE.2011.V3.340. 


\section{Penentuan Jarak Minimum...}

2. Bertetangga artinya dua buah simpul pada graf tidak berarah jika keduanya terhubung dengan sebuah sisi. Dapat dikatakan, jika v1 dan v2 bertetangga, maka haruslah terdapat sisi (v1, v2).

3. Bersisian artinya untuk sebarang sisi e $=(v 1, v 2)$, sisi e dikatakan bersisian dengan titik v1 dan titik v2.

4. Siklus artinya lintasan yang simpul awal dan simpul akhirnya sama.

5. Pohon adalah graf terhubung dengan $\mathrm{n}-1$ sisi dan $\mathrm{n}$ simpul.

Jika $\mathrm{G}$ adalah graf berbobot, maka bobot dari pohon rentang $\mathrm{T}$ dari G didefinisikan sebagai jumlah bobot pada semua sisi di T. Pohon rentang yang berbeda memiliki bobot yang berbeda pula. Di antara semua pohon rentang di G, pohon yang memiliki bobot paling minimum dinamakan pohon rentang minimum. Persoalan pohon rentang minimum menyangkut pemilihan seperangkat penghubung yang menghubungkan semua simpul dalam suatu jaringan sedemikian rupa sehingga menghasilkan jumlah panjang yang minimum dari semua penghubung terpilih ${ }^{3}$.

QM for Windows merupakan perangkat lunak yang dikembangkan dan menyertai buku-buku teks seputar manajemen operasi yang diterbitkan oleh Prentice-Hall's. Terdapat tiga perangkat lunak sejenis yang mereka terbitkan yakni DS for Windows, POM for Windows dan QM for Windows. Perangkatperangkat lunak ini user friendly dalam penggunaannya untuk membantu proses perhitungan secara teknis pengambilan keputusan secara kuantitatif. POM for Windows ialah paket yang diperuntukkan untuk manajemen operasi; QM for Windows ialah paket yang diperuntukkan untuk metode kuantitatif untuk bisnis dan DS for Windows berisi gabungan dari kedua paket sebelumnya.

QM for Windows menyediakan modul-modul dalam area pengambilan keputusan bisnis. Modul yang tersedia pada QM for Windows adalah: Assignment, Breakeven/Cost-Volume Analysis, Decision Analysis, Forecasting, Game Theory, Goal Programming, Integer Programming ,

${ }^{3}$ Jong Jek Siang, Riset Operasi : Dalam Pendekatan Algoritmis -2/E. (Yogyakarta: Andi, 2015), https://openlibrary.telkomuniversity.ac.id/pustaka/99561/riset-operasi-dalampendekatan-algoritmis-2-e-.html.

Al-Khwarizmi - 79 
Inventory, Linear Programming, Markov Analysis, Material Requirements Planning, Mixed Integer Programming, Networks, Project Management (PERT/CPM), Quality Control, Simulation, Statistics, Transportation.

Konsep pohon merupakan konsep penting karena konsep ini mampu mendukung penerapan graf dalam berbagai bidang ilmu. Aplikasi yang menggunakan konsep Pohon diantaranya adalah pembangunan jalan dan rel kereta api, pembuatan jaringan komputer, pencarian jalur untuk penjual keliling, dan sebagainya. Salah satu metode untuk mencari pohon rentang minimum dalam masalah jaringan yang ditemukan oleh Robert C. Prim. Algoritma Prim membentuk pohon rentang minimum dengan langkah per langkah. Pada setiap langkah kita mengambil sisi graf G yang memiliki jarak minimum namun yang terhubung dengan pohon rentang $\mathrm{T}$ yang telah terbentuk ${ }^{4}$.

Misalkan $\mathrm{G}$ adalah graf berlabel dengan $\mathrm{n}$ simpul dan $\mathrm{T}$ adalah pohon rentang minimum yang akan dibentuk (mula-mula kosong). Langkah-langkah Algoritma Prim adalah sebagai berikut 5:

1. Inisialisasi: Mula-mula $\mathrm{T}$ adalah graf kosong

2. Ambil sembarang $v \in V(G)$. Masukkan $v$ ke dalam $V(T)$.

3. $V(G)=V(G)-v$.

4. Untuk itu pilih $\mathrm{i}=1,2, \ldots, \mathrm{n}-1$ :

a) Pilihlah sisi e $\in \mathrm{E}(\mathrm{G})$ dan e $\notin \mathrm{E}(\mathrm{T})$ dengan syarat:

1) e berhubungan dengan satu simpul di $\mathrm{T}$.

2) mempunyai bobot (jarak) terkecil dibandingkan dengan semua sisi yang berhubungan dengan tiap simpul dalam $\mathrm{T}$.

Misalkan w adalah simpul ujung e yang tidak berada dalam T.

b) Tambahkan e ke E(T) dan w ke V (T)

c) $\mathrm{V}(\mathrm{G})=\mathrm{V}(\mathrm{G})-\mathrm{w}$

QM adalah kepanjangan dari quantitatif method yang merupakan perangkat lunak dan menyertai buku-buku teks seputar manajemen operasi.

\footnotetext{
4 R. C. Prim, "Shortest Connection Networks and Some Generalizations," The Bell System Technical Journal 36, no. 6 (November 1957): 1389-1401, https://doi.org/10.1002/j.1538-7305.1957.tb01515.x.

5 Siang, Riset Operasi.
} 


\section{Penentuan Jarak Minimum...}

QM for windows merupakan gabungan dari program terdahulu DS dan POM for windows, jadi jika dibandingkan dengan program POM for windows modul-modul yang tersedia pada QM for windows lebih banyak. Salah satu modulnya adalah Network. Ada 3 macam model network ( Model Jaringan ) yaitu Minimal Spanning Tree, Maximal Flow, Shortest Route. ${ }^{6}$

Minimal Spanning Tree yaitu menentukan jalur yang menghubungkan semua tempat (point) dalam sebuah jaringan sehingga total jaraknya minimal. Misalnya digunakan untuk menentukan cara terbaik (efisien) untuk menghubungkan rumah-rumah dengan jaringan listrik atau pipa air.

Langkah-langkah Penyelesaian QM For Windows

1. Jalankan program QM for Windows, pilih Module - Networks

2. Pilih menu File - New - 1. Minimum Spanning Tree, sehingga muncul tampilan

3. Buat judul penyelesaian soal ini dengan mengisi bagian Title.. Jika Title tidak diisi, program QM for Windows akan membuat judul sendiri sesuai default (patokan)-nya. Default Title ini dapat dirubah dengan meng-klik modify default title . Judul dapat diubah/edit dengan mengklik ikon title.

4. Isikan (set) jumlah jalur dengan 13, dengan cara meng-klik tanda pada kotak Number of Branches

5. Pilih Other pada bagian Row names, kemudian isi dengan nama "Jalur"

6. Sekarang tampilan akan seperti pada Gambar 7.3, lanjutkan dengan meng-klik OK tombol hingga akan muncul tampilan

7. Isikan angka-angka yang sesuai pada kotak-kotak yang bersesuaian antara Jalur (Branch name), Start node, End node dan Cost.

8. Selesaikan Contoh Soal ini dengan meng-klik tombol SOLVE pada toolbar atau dari menu File - Solve, atau dengan menekan tombol F9 pada keyboard.

\footnotetext{
${ }^{6}$ Budi Harsanto, Naskah Tutorial QM For Windows (Bandung: BHS, 2011), 2-3.
}

Al-Khwarizmi - 81 
9. Jika ternyata ada data soal yang perlu diperbaiki, klik tombol EDIT pada toolbar atau dari menu File - Edit

10. Jangan lupa simpan (save) file kerja ini dengan menu File - Save (atau menekan tombol Ctrl+S. Pilihan untuk menyimpan file dengan format Excel (.xls) dan html (.html) juga disediakan.

\section{Metode}

Metode yang digunakan dalam penilitian ini adalah Pendekatan analisis kuantitatif terdiri dari pendefinisian masalah, pengembangan model, perolehan data masukan, pengembangan solusi, pengujian solusi, analisis hasil, dan penerapan hasil.

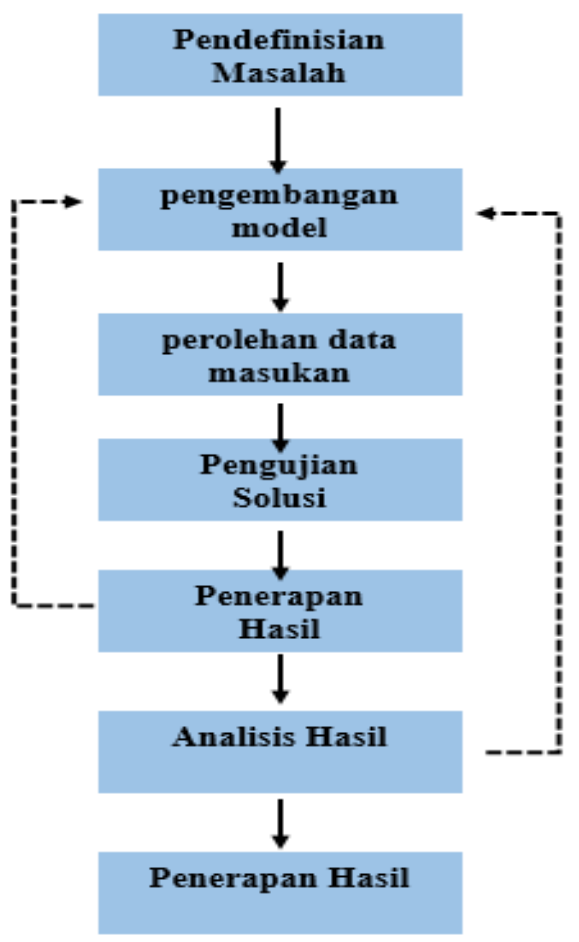

Gambar: Pendekatan analisis kuantitatif

Penelitian ini dilakukan di jalan akasia balandai kota palopo yaitu Perumahan Nelayan. Teknik pengumpulan data yakni dengan observasi dan wawancara. 


\section{Penentuan Jarak Minimum dengan Algoritma Prim}

Perumuahan Nelayan adalah sebuah perumahan yang terletak Jl. Akasia Temmalebba Bara Kota Palopo terdiri dari 43 rumah. Ke-43 rumah tersebut akan dihubungkan dengan jaringan listrik. Tentu dengan mencoba meminimalkan sebanyak mungkin yang digunakan. Denah posisi rumahrumah di "Perumahan Nelayan" beserta jarak antar rumah (Satuan Meter).

Jaringan yang terbentuk diberikan seperti gambar di bawah ini:

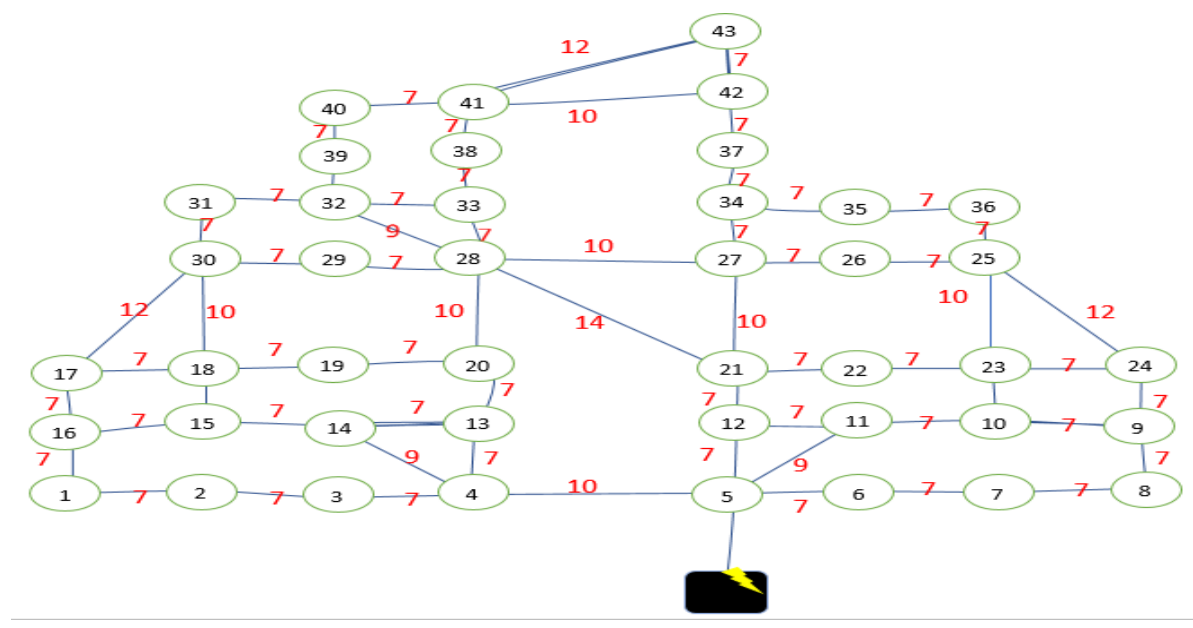

Gambar 2. Perumahan nelayan.

Keterangan: Angka dalam lingkaran menunjukkan rumah-rumah. Angka di garis menunjukkan jarak antar rumah, dalam meter

Penerapan Algoritma Prim untuk masalah di atas menghasilkan gambar sebagai berikut:

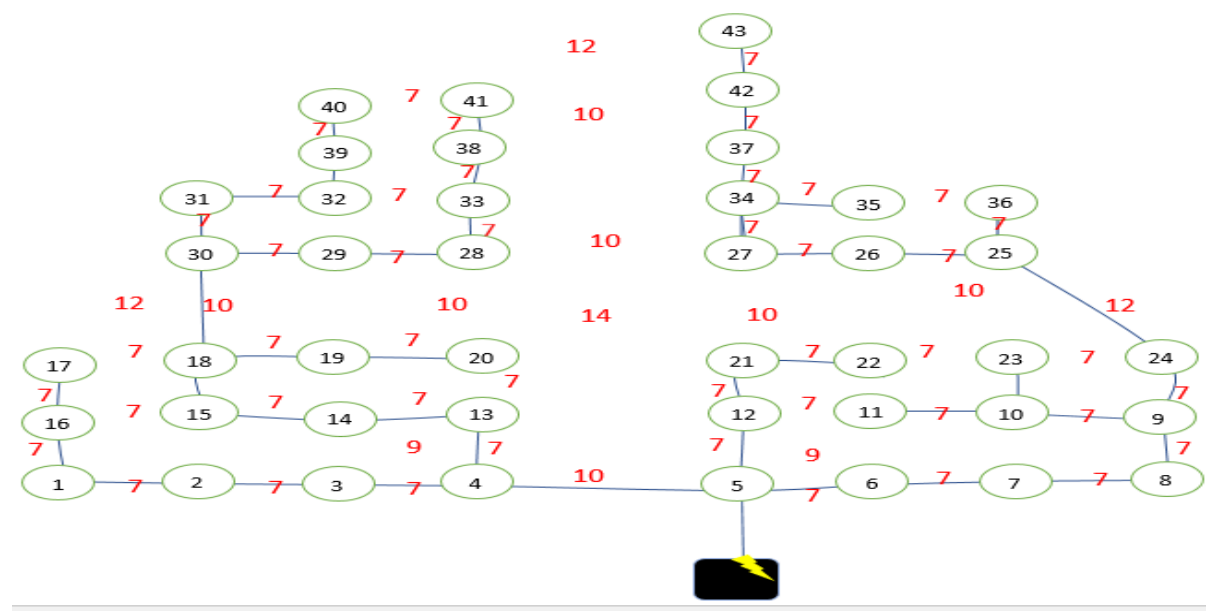

Gambar 3. Pohon Rentang Minimum dengan Algoritma Prim Al-Khwarizmi - 83 
Dari hasil di Gambar 3 diperoleh jarak yang dapat meminamalkan penggunaan kabel seperti pada permasalahan diatas pada perumahan nelayan hanya menggunakan 300 meter.

\section{Penentuan Jarak Minimum dengan QM for Windows}

Dalam bagian ini akan dibahas aplikasi dari $Q M$ for Windows untuk menyelesaikan masalah pemdistribusian listrik di Perumahan Nelayan. $Q M$ For windows bertujuan jalur yang harus dilewati listrik sehingga berpengaruh terhadap total jarak. Permasalahan di atas dapat dimodelkan menjadi tabel:

Ada 61 jalur dalam gambar

\begin{tabular}{|c|c|c|c|}
\hline Jalur 1 & 1 & 2 & 7 \\
\hline Jalur 2 & 1 & 16 & 7 \\
\hline Jalur 3 & 2 & 3 & 7 \\
\hline Jalur 4 & 3 & 4 & 7 \\
\hline Jalur 5 & 4 & 5 & 10 \\
\hline Jalur 6 & 4 & 13 & 7 \\
\hline Jalur 7 & 4 & 14 & 9 \\
\hline Jalur 8 & 5 & 6 & 7 \\
\hline Jalur 9 & 5 & 11 & 9 \\
\hline Jalur 10 & 5 & 12 & 7 \\
\hline Jalur 11 & 6 & 7 & 7 \\
\hline Jalur 12 & 7 & 8 & 7 \\
\hline Jalur 13 & 8 & 9 & 7 \\
\hline Jalur 14 & 9 & 10 & 7 \\
\hline Jalur 15 & 9 & 24 & 7 \\
\hline Jalur 16 & 10 & 11 & 7 \\
\hline Jalur 17 & 10 & 23 & 7 \\
\hline Jalur 18 & 11 & 12 & 7 \\
\hline Jalur 19 & 12 & 21 & 7 \\
\hline Jalur 20 & 13 & 14 & 7 \\
\hline Jalur 21 & 14 & 15 & 7 \\
\hline Jalur 22 & 15 & 16 & 7 \\
\hline
\end{tabular}

\begin{tabular}{|c|c|c|c|}
\hline Jalur 23 & 15 & 18 & 7 \\
\hline Jalur 24 & 16 & 17 & 7 \\
\hline Jalur 25 & 17 & 18 & 7 \\
\hline Jalur 26 & 17 & 30 & 12 \\
\hline Jalur 27 & 18 & 19 & 7 \\
\hline Jalur 28 & 18 & 30 & 10 \\
\hline Jalur 29 & 19 & 20 & 7 \\
\hline Jalur 29 & 20 & 28 & 10 \\
\hline Jalur 30 & 21 & 22 & 7 \\
\hline Jalur 31 & 21 & 27 & 10 \\
\hline Jalur 32 & 21 & 28 & 14 \\
\hline Jalur 33 & 22 & 23 & 7 \\
\hline Jalur 34 & 23 & 24 & 7 \\
\hline Jalur 35 & 23 & 25 & 10 \\
\hline Jalur 36 & 24 & 25 & 7 \\
\hline Jalur 37 & 25 & 26 & 7 \\
\hline Jalur 38 & 25 & 36 & 7 \\
\hline Jalur 39 & 26 & 27 & 7 \\
\hline Jalur 40 & 27 & 34 & 7 \\
\hline Jalur 41 & 27 & 28 & 10 \\
\hline Jalur 42 & 28 & 29 & 7 \\
\hline Jalur 43 & 28 & 33 & 7 \\
\hline
\end{tabular}

\begin{tabular}{|c|c|c|c|}
\hline Jalur 44 & 28 & 32 & 9 \\
\hline Jalur 45 & 29 & 30 & 7 \\
\hline Jalur 46 & 30 & 31 & 7 \\
\hline Jalur 47 & 31 & 32 & 7 \\
\hline Jalur 48 & 32 & 33 & 7 \\
\hline Jalur 49 & 32 & 39 & 7 \\
\hline Jalur 50 & 33 & 38 & 7 \\
\hline Jalur 51 & 34 & 35 & 7 \\
\hline Jalur 52 & 34 & 37 & 7 \\
\hline Jalur 53 & 35 & 36 & 7 \\
\hline Jalur 54 & 37 & 42 & 7 \\
\hline Jalur 55 & 38 & 41 & 7 \\
\hline Jalur 56 & 39 & 40 & 7 \\
\hline Jalur 57 & 40 & 41 & 7 \\
\hline Jalur 58 & 41 & 42 & 10 \\
\hline Jalur 59 & 41 & 43 & 12 \\
\hline Jalur 60 & 42 & 43 & 7 \\
\hline Jalur 61 & 42 & 43 & 7 \\
\hline
\end{tabular}

Dengan menggunakan QM FOR WINDOWS yaitu module Network minumum soanning tree di peroleh:

1. Network result 
Penentuan Jarak Minimum...

\begin{tabular}{|c|c|c|c|c|c|}
\hline \multicolumn{6}{|l|}{1000 Solution } \\
\hline Branch name & Start node & End node & Cost & Include & Cost \\
\hline jalur 1 & 1 & 2 & 7 & $\mathrm{Y}$ & 7 \\
\hline jalur 2 & 1 & 16 & 7 & $Y$ & 7 \\
\hline jalur 3 & 2 & 3 & 7 & $Y$ & 7 \\
\hline jalur 4 & 3 & 4 & 7 & Y & 7 \\
\hline jalur 5 & 4 & 5 & 10 & $Y$ & 10 \\
\hline jalur 6 & 4 & 13 & 7 & $\mathrm{Y}$ & 7 \\
\hline jalur 7 & 4 & 14 & 9 & & \\
\hline jalur 8 & 5 & 6 & 7 & $\mathrm{Y}$ & 7 \\
\hline jalur 9 & 5 & 11 & 9 & & \\
\hline jalur 10 & 5 & 12 & 0 & $\mathrm{Y}$ & 0 \\
\hline jalur 11 & 6 & 7 & 7 & $\mathrm{Y}$ & 7 \\
\hline jalur 12 & 7 & 8 & 7 & $Y$ & 7 \\
\hline jalur 13 & 8 & 9 & 7 & $\mathrm{Y}$ & 7 \\
\hline jalur 14 & 9 & 10 & 7 & $Y$ & 7 \\
\hline jalur 15 & 9 & 24 & 7 & $Y$ & 7 \\
\hline jalur 16 & 10 & 11 & 7 & $Y$ & 7 \\
\hline jalur 17 & 10 & 23 & 7 & $Y$ & 7 \\
\hline Branch name & Start node & End node & Cost & Include & Cost \\
\hline jalur 18 & 11 & 12 & 7 & 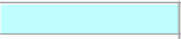 & 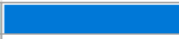 \\
\hline jalur 19 & 12 & 21 & 7 & $Y$ & 7 \\
\hline jalur 20 & 13 & 14 & 7 & $\mathrm{Y}$ & 7 \\
\hline jalur 21 & 14 & 15 & 7 & $Y$ & 7 \\
\hline jalur 22 & 15 & 16 & 7 & & \\
\hline jalur 23 & 15 & 18 & 7 & $Y$ & 7 \\
\hline jalur 24 & 16 & 17 & 7 & $Y$ & 7 \\
\hline jalur 25 & 17 & 18 & 7 & & \\
\hline jalur 26 & 17 & 30 & 12 & & \\
\hline jalur 27 & 18 & 19 & 7 & $Y$ & 7 \\
\hline jalur 28 & 18 & 30 & 10 & $Y$ & 10 \\
\hline jalur 29 & 19 & 20 & 7 & $Y$ & 7 \\
\hline jalur 29 & 20 & 28 & 10 & & \\
\hline jalur 30 & 21 & 22 & 7 & $Y$ & 7 \\
\hline jalur 31 & 21 & 27 & 10 & & \\
\hline jalur 32 & 21 & 28 & 14 & & \\
\hline jalıır 3.3 & 22 & 23 & 7 & & \\
\hline jalur 34 & 23 & 24 & 7 & & \\
\hline jalur 35 & 23 & 25 & 10 & & \\
\hline jalur 36 & 24 & 25 & 7 & $Y$ & 7 \\
\hline jalur 37 & 25 & 26 & 7 & $Y$ & 7 \\
\hline jalur 38 & 25 & 36 & 7 & $Y$ & 7 \\
\hline jalur 39 & 26 & 27 & 7 & $Y$ & 7 \\
\hline jalur 40 & 27 & 34 & 7 & $Y$ & 7 \\
\hline jalur 41 & 27 & 28 & 10 & & \\
\hline jalur 42 & 28 & 29 & 7 & $Y$ & 7 \\
\hline jalur 43 & 28 & 33 & 7 & $Y$ & 7 \\
\hline jalur 44 & 28 & 32 & 9 & & \\
\hline jalur 45 & 29 & 30 & 7 & $Y$ & 7 \\
\hline jalur 46 & 30 & 31 & 7 & $Y$ & 7 \\
\hline jalur 47 & 31 & 32 & 7 & $Y$ & 7 \\
\hline jalur 48 & 32 & 33 & 7 & & \\
\hline jalur 49 & 32 & 39 & 7 & $Y$ & 7 \\
\hline jalur 50 & 33 & 38 & 7 & $Y$ & 7 \\
\hline jalur 51 & 34 & 35 & 7 & $Y$ & 7 \\
\hline jalur 52 & 34 & 37 & 7 & $Y$ & 7 \\
\hline jalur 53 & 35 & 36 & 7 & & \\
\hline jalur 54 & 37 & 42 & 7 & $Y$ & 7 \\
\hline jalur 55 & 38 & 41 & 7 & $Y$ & 7 \\
\hline jalur 56 & 39 & 40 & 7 & $Y$ & 7 \\
\hline jalur 57 & 40 & 41 & 7 & & \\
\hline jalur 58 & 41 & 42 & 10 & & \\
\hline jalur 59 & 41 & 43 & 12 & & \\
\hline jalur 60 & 42 & 43 & 7 & $Y$ & 7 \\
\hline jalur 61 & 42 & 43 & 7 & & \\
\hline Total & & & & & 300 \\
\hline lution Screen & & & Taylor's Introduc & ction to Managen & ment Science Text \\
\hline
\end{tabular}

Total kebel yang di gunakan adalah $300 \mathrm{M}$ 


\section{Solution step}

\begin{tabular}{|c|c|c|c|c|}
\hline Branch & $\begin{array}{l}\text { Starting } \\
\text { node }\end{array}$ & $\begin{array}{l}\text { Ending } \\
\text { node }\end{array}$ & Cost & $\begin{array}{l}\text { Cumulative } \\
\text { cost }\end{array}$ \\
\hline jalur 1 & 1 & 2 & 7 & 7 \\
\hline jalur 2 & 1 & 16 & 7 & 14 \\
\hline jalur 3 & 2 & 3 & 7 & 21 \\
\hline jalur 4 & 3 & 4 & 7 & 28 \\
\hline jalur 6 & 4 & 13 & 7 & 35 \\
\hline jalur 20 & 13 & 14 & 7 & 42 \\
\hline jalur 21 & 14 & 15 & 7 & 49 \\
\hline jalur 23 & 15 & 18 & 7 & 56 \\
\hline jalur 24 & 16 & 17 & 7 & 63 \\
\hline jalur 27 & 18 & 19 & 7 & 70 \\
\hline jalur 29 & 19 & 20 & 7 & 77 \\
\hline jalur 5 & 4 & 5 & 10 & 87 \\
\hline jalur 10 & 5 & 12 & $\mathrm{O}$ & 87 \\
\hline jalur 8 & 5 & 6 & 7 & 94 \\
\hline jalur 11 & 6 & 7 & 7 & 101 \\
\hline jalur 12 & 7 & 8 & 7 & 108 \\
\hline jalur 13 & 8 & 9 & 7 & 115 \\
\hline jalur 14 & 9 & 10 & 7 & 122 \\
\hline jalur 15 & 9 & 24 & 7 & 129 \\
\hline jalur 16 & 10 & 11 & 7 & 136 \\
\hline jalur 17 & 10 & 23 & 7 & 143 \\
\hline jalur 19 & 12 & 21 & 7 & 150 \\
\hline jalur 30 & 21 & 22 & 7 & 157 \\
\hline jalur 36 & 24 & 25 & 7 & 164 \\
\hline jalur 37 & 25 & 26 & 7 & 171 \\
\hline jalur 38 & 25 & 36 & 7 & 178 \\
\hline jalur 39 & 26 & 27 & 7 & 185 \\
\hline jalur 40 & 27 & 34 & 7 & 192 \\
\hline jalur 51 & 34 & 35 & 7 & 199 \\
\hline jalur 52 & 34 & 37 & 7 & 206 \\
\hline jalur 54 & 37 & 42 & 7 & 213 \\
\hline jalur 60 & 42 & 43 & 7 & 220 \\
\hline
\end{tabular}

\begin{tabular}{|l|r|r|r|r|}
\hline jalur 28 & 18 & 30 & 10 & 237 \\
\hline jalur 45 & 29 & 30 & 7 & 244 \\
\hline jalur 42 & 28 & 29 & 7 & 251 \\
\hline jalur 43 & 28 & 33 & 7 & 258 \\
\hline jalur 46 & 30 & 31 & 7 & 265 \\
\hline jalur 47 & 31 & 32 & 7 & 272 \\
\hline jalur 49 & 32 & 39 & 7 & 279 \\
\hline jalur 50 & 33 & 38 & 7 & 286 \\
\hline jalur 55 & 38 & 41 & 7 & 293 \\
\hline jalur 56 & 39 & 40 & 7 & 300 \\
\hline
\end{tabular}

Jadi rangkaian jaringan listrik di Perumahan Nelayan : 


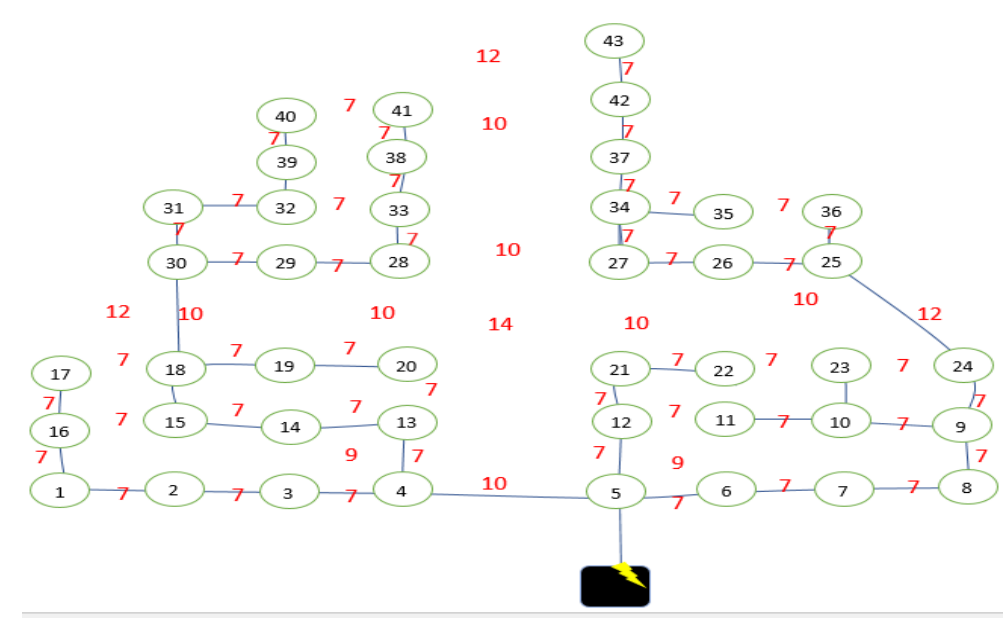

Gambar

Terlihat bahwa QM for windows menghasilkan pohon rentang minimum yang sama dengan Algoritma Prim, sehingga diperoleh total kabel yan digunakan sama yakni 300 meter.

\section{Simpulan}

\section{Penutup}

Dari pembahasan pada penelitian ini, diperoleh beberapa kesimpulan sebagai berikut:

1. Algoritma Prim \& $Q M$ for Windows dapat digunakan untuk menyelesaikan masalah kasus pendistribusian listrik di Perumahan Nelayan dikota Palopo.

2. Algoritma Prim dapat menghasilkan jarak minimum (300 M) pada jaringan pendistribusian listrik di Perumhan Nelayan kota Palopo.

3. QM for Windows dapat menghasilkan jarak minimum (300 M) pada jaringan pendistribusian listrik di Perumhan Nelayan Palopo.

\section{Saran}

Algoritma Prim dan QM for Windows efektif untuk menyelesaikan permasalahan jaringan dengan hasil akhir berupa pohon rentang minimum. Dalam kasus jaringan listrik atau jaringan lainnya kedua metode ini dapat digunakan sebagai salah satu perencanaan yang baik karena dapat mereduksi biaya. Algoritma Prim maupun $Q M$ for Windows dapat menjadi 
rujukan bagi organisasi/perusahaan dalam hal pemetaan sebuah jaringan yang akan dibangun/dibentuk.

\section{Daftar Pustaka}

Budi Harsanto. Naskah Tutorial QM For Windows. Bandung: BHS, 2011.

Prim, R. C. "Shortest Connection Networks and Some Generalizations." The Bell System Technical Journal 36, no. 6 (November 1957): 1389-1401. https://doi.org/10.1002/j.1538-7305.1957.tb01515.x.

Siang, Jong Jek. Riset Operasi: Dalam Pendekatan Algoritmis -2/E. Yogyakarta: $\quad$ Andi, 2015. https://openlibrary.telkomuniversity.ac.id/pustaka/99561/risetoperasi-dalam-pendekatan-algoritmis-2-e-.html.

T., Arogundade O., Sobowale B., and Akinwale A. T. "Prim Algorithm Approach to Improving Local Access Network in Rural Areas." International Journal of Computer Theory and Engineering, 2011, 41317. https://doi.org/10.7763/IJCTE.2011.V3.340.

Taha, Hamdy A. Operations Research An Introduction. 9th ed. London: Pearson International, 2011. 